\title{
A prospective study of acute cerebrovascular disease in the community: the Oxfordshire Community Stroke Project 1981-86 1. Methodology, demography and incident cases of first-ever stroke
}

\author{
JOHN BAMFORD, * PETER SANDERCOCK, * MARTIN DENNIS,** \\ CHARLES WARLOW, $*$ LESLEY JONES, $\dagger$ KLIM McPHERSON, $\dagger$ \\ MARTIN VESSEY, $\dagger$ GODFREY FOWLER, $\dagger$ ANDREW MOLYNEUX, $\ddagger$ \\ TREVOR HUGHES,§ JOHN BURN,\| DERICK WADE\|
}

From the Departments of Clinical Neurology, ${ }^{*}$ Community Medicine and General Practice, $\dagger$ Neuroradiology, $\ddagger$ and Neuropathology,§ Radcliffe Infirmary, Oxford, and Rivermead Rehabilitation Centre, Oxford, UK\|

SUMMARY A prospective study of acute cerebrovascular disease in a community of about 105,000 people is reported. The study protocol combined rapid clinical assessment of patients with accurate diagnosis of the pathological type of stroke by CT or necropsy, whether or not they were admitted to hospital. The study population was defined as those people who were registered with one of 50 collaborating general practitioners (GPs). Referrals to the study were primarily from the GPs though, to ensure complete case ascertainment, hospital casualty and admission registers, death certificates and special data from the Oxford Record Linkage Study were also scrutinised. Six hundred and seventy five cases of clinically definite first-ever in a lifetime stroke were registered in four years yielding a crude annual incidence of $1 \cdot 60 / 1,000$ or $2 \cdot 00 / 1,000$ when adjusted to the 1981 population of England and Wales. The age and sex specific incidence rates for first stroke showed a steep rise with age for both sexes. The odds of a male sustaining a first stroke were $26 \%$ greater than those of a female. Ninety one per cent of patients were examined in a median time of four days after the event by a study neurologist and $88 \%$ had cerebral CT or necropsy.

Over the last 25 years there have been many studies of stroke incidence throughout the world. The methods used in community-based studies have varied from detailed retrospective case note reviews (for example Rochester, USA ${ }^{12}$ ), through cohort studies (such as Framingham, USA ${ }^{3}$ and Hisayama, Japan ${ }^{4}$ ) to prospective stroke registers in defined populations (for example, Tilburg, Holland ${ }^{5}$ and Shibata, $\operatorname{Japan}^{6}$ ) and despite the methodological difficulties of measuring stroke incidence accurately, ${ }^{7}$ the magnitude of the clinical, social and economic problems associated with stroke has been well established. Studies of Caucasians

Address for reprint requests: Professor Warlow, Department of Clinical Neurosciences, Western General Hospital, Crewe Road, Edinburgh EH4 2XU, UK.

Received 18 September 1987 and in revised form 21 June 1988. Accepted 1 July 1988 in Europe and North America have shown crude annual incidence rates for first-ever in a lifetime stroke (hereafter referred to as first-ever stroke) of between 1.5 and 2.5 per 1,000 though the time-trend data from Rochester show a steady decline over several decades. ${ }^{8}$ All studies have shown a steep rise in incidence with increasing age. The major risk factors for stroke (hypertension, transient ischaemic attack (TIA), heart disease and diabetes mellitus) have been identified repeatedly, albeit with varying relative and population attributable risks. However, for clinical purposes more accurate and detailed epidemiological data are needed since stroke is not a single pathological entity. If effective treatments are to be developed, more attention must be focused on identifying and studying the outcome of pathologically homogeneous groups.

The Oxfordshire Community Stroke Project (OCSP) was established to determine the incidence, 
risk factors and outcome of first-ever stroke and TIA in a population unbiased by hospital admission or outpatient referral practice. We attempted to obtain a computed tomographic (CT) scan or necropsy on every patient to establish the pathological type of stroke and to enable accurate clinico-pathological correlations to be made. The present communication describes the study methods and presents the basic details of both the study population and the patients with first-ever stroke. Future communications will deal with the incidence and outcome of the pathological subtypes of stroke and also the incidence and prognosis of TIA.

\section{Methodology}

\section{Study population}

This comprised all patients who were fully registered with $\mathbf{5 0}$ General Practitioners (GPs) based in 10 health centres who collaborated in the study (see acknowledgements). In the UK, patients register with a GP who provides their primary health care and, when necessary, refers them for specialist advice. The GP receives all relevant information about specialist consultations and hospital admissions even if these do not occur locally. Thus the record held by the GP forms a lifelong record of all medical events (at least since the establishment of the National Health Service (NHS) in 1948) as well as recording details of each consultation with the GP (including blood pressure recordings, blood counts etc). This individual record is transferred to a new GP if the patient moves residence. The practices who collaborated in the study were chosen if they were (a) in Oxfordshire (b) had an accurate age-sex register (ASR) of all patients registered with them (c) were willing to notify all patients with possible acute cerebrovascular disease to the study and (d) were enthusiastic to collaborate. The GPs provided primary health care for both urban and rural communities (fig 1) and since they all accepted a full range of patients onto their lists the study population was not restricted to any particular socio-economic group. A census of the ASRs was performed in 1981 and again in 1986 and the average value of the numbers registered at these times, in 10 year age bands according to sex, was used as the denominator for the study. The results of the censuses were validated by comparing them with the data available for the age bands 0-64, 65-74 and 75 + years from the independent records of the local Family Practitioner Committee (FPC) which are used to determine the remuneration of GPs. It was impractical to use the FPC figures themselves since these records were not computerised and were split into the above age-bands only.

\section{Duration of the study}

Registration of patients began on 1 November 1981 and continued until 31 October 1986 . Partly because of problems in obtaining continuous funding and partly to allow interim analyses to be performed, the registration of cases of stroke was suspended between 1 November 1984 and 31 October 1985 though the registration of patients with TIA and the follow up of patients already registered continued during this time. Registration of stroke and TIA patients finally ended on 31 October 1986 though the referral of patients and surveillance of admission books etc continued for a further two months to ensure the registration of all patients whose stroke or TIA occurred on or before 31 October 1986. Therefore, the study registered patients with first-ever stroke over a period of four years whereas patients with TIA were registered over five years. The follow up for non-fatal events and assessment of handicap and disability will continue until 1989; mortality follow up for all patients still alive at that point will continue indefinitely via the NHS central registry at Southport.

\section{Case ascertainment}

The collaborating GPs notified the study office of any patient whom they thought might have had an episode of acute neurological dysfunction caused by cerebrovascular disease irrespective of from whom or where the patient obtained further medical care. Patients who suffered a first-ever stroke whilst temporarily away from Oxfordshire but who were registered with a collaborating GP were included. Patients

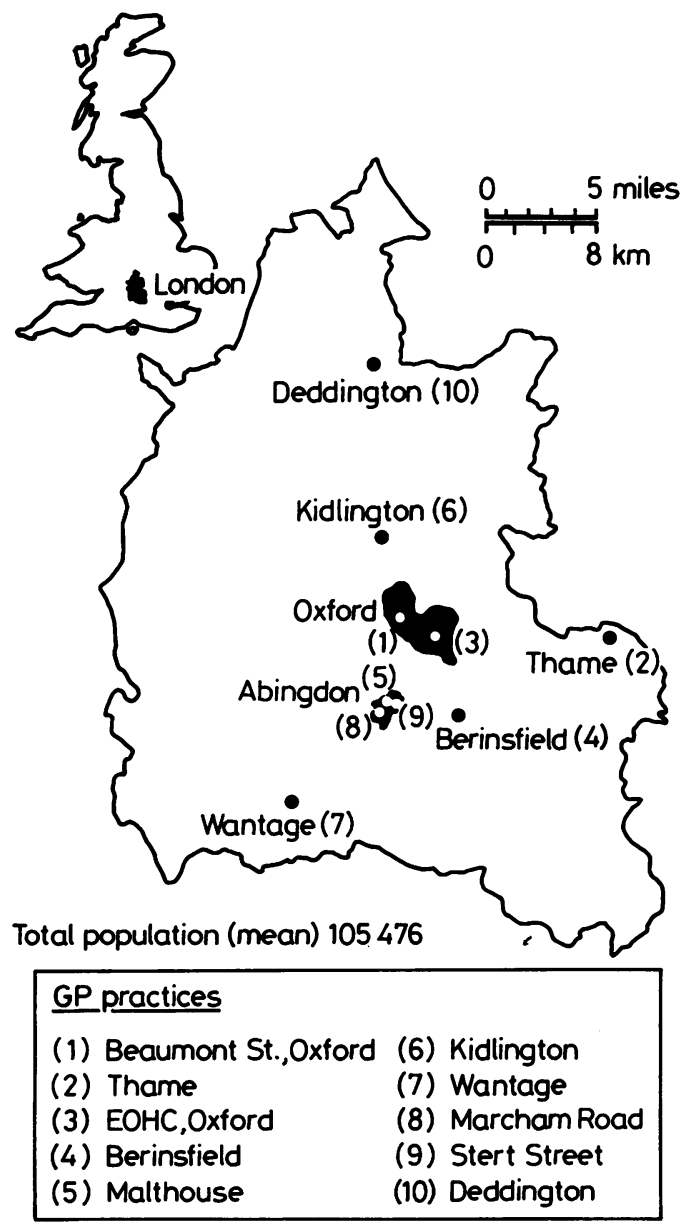

Fig 1 The geographical distribution of the general practices which collaborated in the Oxfordshire Community Stroke Project. 
who were not fully registered with a collaborating GP at the time of their stroke (for example patients who were visiting Oxfordshire and who registered temporarily after the event) were excluded. A liason GP in each practice regularly checked with colleagues to ensure that all relevant patients had been referred. The study team maintained frequent personal contact with all the GPs and our research nurses visited each practice at least once a week. A monthly newsletter was sent to all collaborators and GPs received a report on each of their patients referred to the study.

The admission and casualty registers of each hospital in the Oxford area were checked frequently to identify patients who had attended or been admitted without their GPs knowledge. The Oxford Record Linkage Study (ORLS) ${ }^{9}$ enabled all patients with a given diagnosis who died in, or were discharged from, a hospital in the Oxford region to be identified. The ORLS provided lists of patients with diagnoses coded to the International Classification of Diseases (9th Revision) rubrics 430 to 438 inclusive and rubric 342. Finally, copies of the death certificates of all residents of Oxfordshire were examined and copies of necropsy reports obtained.

\section{Patient assessment}

The patients were assessed as soon as possible after the event by a study neurologist (PS, JB, MD, CW) either in hospital, in a special outpatient clinic or at home. In addition to a standard neurological history and examination, an estimate of pre-stroke handicap and disability was made. The GP and hospital medical records were reviewed to check details of previous illness. A particular search was made for evidence of previous cerebrovascular events and to obtain data on any risk factors documented before the stroke. If a patient died very rapidly we attempted to obtain an eye witness account as well as using information recorded in the GP and hospital notes.

\section{Definitions}

Stroke was defined as rapidly developing clinical symptoms and/or signs of focal, and at times global (applied to patients in deep coma and to those with subarachnoid haemorrhage), loss of cerebral function, with symptoms lasting more than 24 hours or leading to death, with no apparent cause other than that of vascular origin (after Hatano).$^{10}$ A TIA was defined as an acute loss of focal cerebral or ocular function with symptoms lasting less than 24 hours and which after adequate investigation was presumed to be due to embolic or thrombotic vascular disease. " Patients were only included in the study if they had had a clinically apparent first-ever stroke or TIA.

\section{Pathological diagnosis}

We attempted to obtain a CT or necropsy examination in every case. In view of the possible risks ${ }^{12} \mathrm{CT}$ was only performed with intravenous contrast if clinically indicated, initially using an EMI $1007160 \times 160$ matrix scanner and, from early 1984 , a Siemens Somaton DR1 scanner. CT scans were reported without knowledge of the clinical details of the stroke by the study neuroradiologist (AM).

\section{Investigations}

Whenever possible the following investigations were performed: full blood count, erythrocyte sedimentation rate, blood urea and electrolytes, glucose, cholesterol, triglycerides, syphilis serology, electrocardiograph and chest radiography. Many patients had an echocardiogram performed as part of a parallel study.

\section{Follow up}

All cases were followed prospectively. Our research nurses personally interviewed survivors in their place of residence at 1 month, 6 months and 12 months and then annually from the time of the stroke, using a standardised questionnaire designed to detect recurrent cerebrovascular and cardiovascular events. If a recurrent stroke was suspected the study neurologist re-examined the patient. The nurses administered a number of simple rating scales to all patients which were designed to measure disability and handicap. At various times more detailed information on functional ability, activities of daily living, psychological and social functioning and the impact on the chief carer were recorded on consecutive series of patients. This information formed the basis of a number of substudies which will be reported independently. Details of the use of health care resources and placement were recorded throughout the study. If the patient died, all available medical records were reviewed and a necropsy obtained whenever possible to ascertain the cause of death.

\section{Data collection and analysis}

All data were collected on precoded forms and entered onto the University of Oxford ICL 2988 and Digital VAX computers. They were analysed using the SPSS ${ }^{13}$ package. The confidence interval of odds ratios were calculated according to Miettinin. ${ }^{14}$ The pooled odds ratio and confidence interval of that ratio for age and sex differences were calculated using the method of Yusuf $e t$ al. ${ }^{15}$

\section{Results}

The results of the 1981 and 1986 ASR censuses of the study population are shown in table 1 . The study population derived from the ASRs was $1 \cdot 1 \%(95 \% \mathrm{CI}$ $1 \cdot 0-1 \cdot 2)$ less than that from the FPC in 1981 and $2.3 \%$ (95\% CI 2.2-2.4) greater in 1986. Figure 2 compares the age and sex distribution of the OCSP population with that of England and Wales in $1981 .^{16}$

Over the five years 1818 patients were notified to the study, 1306 with suspected stroke and 512 with

Table 1 Study population

\begin{tabular}{|c|c|c|c|c|c|c|c|}
\hline \multirow{2}{*}{$\begin{array}{l}\text { Age } \\
\text { (yr) }\end{array}$} & \multicolumn{2}{|l|}{1981} & \multicolumn{2}{|l|}{1986} & \multicolumn{3}{|c|}{ Average } \\
\hline & $M$ & $F$ & $M$ & $F$ & $M$ & $F$ & Total \\
\hline $\begin{array}{r}0-14 \\
15-24 \\
25-34 \\
35-44 \\
45-54 \\
55-64 \\
65-74 \\
75-84 \\
85+ \\
\text { Total }\end{array}$ & $\begin{array}{r}9598 \\
11098 \\
8888 \\
7006 \\
5409 \\
4710 \\
3360 \\
1508 \\
288 \\
51865\end{array}$ & $\begin{array}{r}9132 \\
9240 \\
8319 \\
6827 \\
5279 \\
4796 \\
3776 \\
2472 \\
907 \\
50748\end{array}$ & $\begin{array}{r}9912 \\
11315 \\
9355 \\
8244 \\
5781 \\
4794 \\
3234 \\
1547 \\
282 \\
54464\end{array}$ & $\begin{array}{r}9299 \\
10416 \\
8946 \\
7995 \\
5492 \\
4782 \\
3763 \\
2420 \\
763 \\
53876\end{array}$ & $\begin{array}{r}9754 \\
11206 \\
9122 \\
7625 \\
5595 \\
4752 \\
3297 \\
1528 \\
285 \\
53164\end{array}$ & $\begin{array}{r}9215 \\
9828 \\
8632 \\
7411 \\
5386 \\
4789 \\
3770 \\
2446 \\
835 \\
52312\end{array}$ & $\begin{array}{r}18969 \\
21034 \\
17754 \\
15036 \\
10981 \\
9541 \\
7067 \\
3974 \\
1120 \\
105476\end{array}$ \\
\hline
\end{tabular}

(From the age-sex registers of the collaborating GPs). 


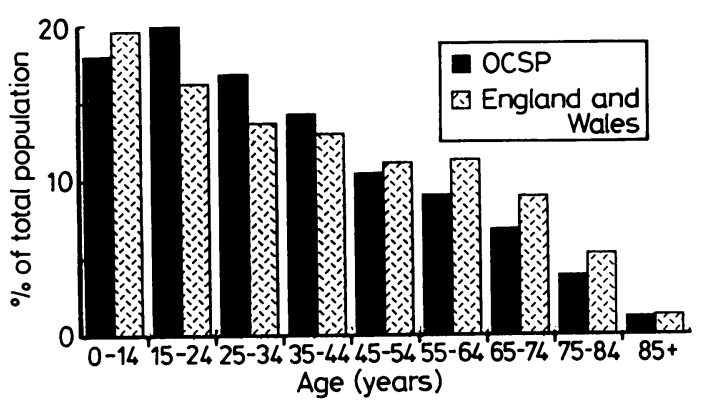

Fig 2 Comparison of the age and sex structures of the study population (average during the study) with that of England and Wales (1981 census). ${ }^{16}$

suspected TIA. After clinical assessment by a study neurologist 682 were considered to have had a firstever stroke (of whom seven [ $1 \%$ ] were later excluded because non-vascular pathology at a site appropriate to the clinical features was detected by CT or at necropsy-vide infra) and 184 an incident TIA. The commonest reasons for exclusion of patients referred with suspected stroke were that the event was not the first-ever stroke, that the patient was only a temporary resident in Oxfordshire or that they had non-vascular cerebral pathololgy. Amongst patients referred with suspected TIA the commonest reason for exclusion was the lack of clear evidence of focal neurological dysfunction. Patients with focal epilepsy, isolated vertigo, transient global amnesia and migraine were also frequently referred as possible TIA.

The number of patients registered with a first-ever stroke over each of the four years was 168, 160, 187 and 160 , a total of 675 . There were $357(52.9 \%)$ females and $318(47 \cdot 1 \%)$ males. The source of first referral of these patients was the GP in $571(84.6 \%)$, hospital admission book searches in $62(9.2 \%)$, ORLS in $11(1.6 \%)$, death certificate searches in $12(1.8 \%)$ and other sources in $19(2 \cdot 8 \%)$. The ORLS and death certificate searches proved useful only in identifying the few patients who had their stroke whilst in hospital after being admitted with some other condition or who had died whilst away from Oxfordshire.

A study neurologist examined 615 of $675(91 \cdot 1 \%)$ patients. The interval from onset of symptoms to assessment is shown in fig 3, the median time being 4 days. Of the remaining 60 patients, $49(82 \%)$ were dead at the time of first notification to the study and a further eight $(13 \%)$ died after notification but before the study neurologist was able to visit. Only three of $675(0.4 \%)$ patients refused to be examined; data on the clinical features were extracted from the GP and hospital records in these cases.

Amongst the $\mathbf{6 7 5}$ patients with a first-ever stroke $542(80 \cdot 3 \%)$ had CT performed. The reasons for not

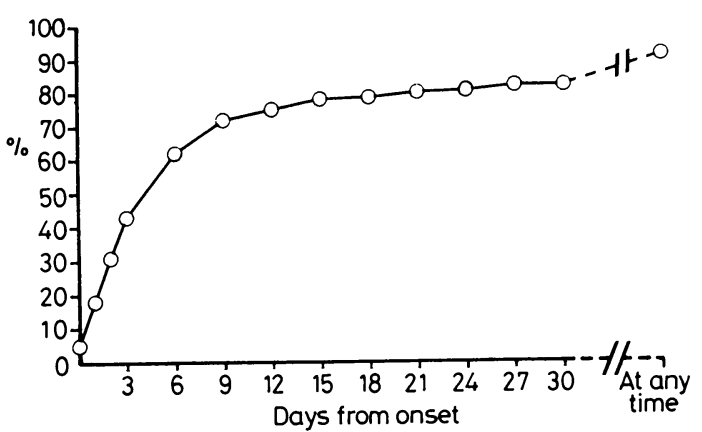

Fig 3 The interval between stroke onset and assessment by a study neurologist. (Day $0=$ day of stroke) $N=675$.

obtaining a CT scan were: rapidity of death in 44 $(6.5 \%)$, the patient was too ill to transfer for the scan in $62(9.2 \%)$, refusal by the patient or their relatives in $16(2.4 \%)$ and miscellaneous reasons in $11(1.6 \%)$. Eighty seven of the $133(65.4 \%)$ patients not having CT were over 75 years of age. Of the 200 patients who have died so far, $77(38.5 \%)$ have had a necropsy examination of whom $54(27 \%)$ had not had CT. Therefore, only 79 of $675(11.7 \%)$ patients had neither CT nor necropsy. Seven patients $(1 \%)$ had subarachnoid haemorrhage confirmed by lumbar puncture alone. Seven patients amongst the $682(1 \%)$ thought to have had a stroke on clinical grounds alone were shown subsequently by CT or necropsy to have nonstroke pathology: two had a primary cerebral tumour, two had metastatic cerebral deposits and three had a subdural haematoma.

The crude annual incidence of first-ever stroke was $1.60 / 1,000(95 \%$ CI $1.48-1.72)$ and $2.00 / 1,000$ persons when adjusted by age and sex to the 1981 population of England and Wales. ${ }^{16}$ The age- and sex-specific incidence rates for first-ever stroke with confidence intervals are shown in fig 4 and detailed in table 2 . The

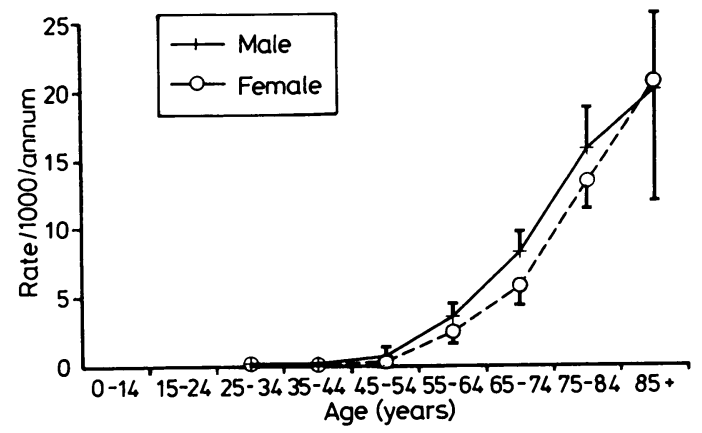

Fig 4 The age and sex specific incidence rates for first-ever stroke in the Oxfordshire Community Stroke Project. (The vertical lines represent one half of the $95 \%$ confidence intervals). $N=675$. 
Table 2 Age-sex specific annual incidence rates per 1000 population for first-ever stroke

\begin{tabular}{|c|c|c|c|c|c|c|c|}
\hline \multirow[b]{2}{*}{ Age (yr) } & \multicolumn{2}{|c|}{ Male } & \multicolumn{2}{|c|}{ Female } & \multicolumn{3}{|c|}{ Total } \\
\hline & $N$ & Rate & $N$ & Rate & $N$ & Rate & \\
\hline $\begin{array}{l}0-14 \\
15-24 \\
25-34 \\
35-44 \\
<45 \\
45-54 \\
55-64 \\
65-74 \\
75-84 \\
85+ \\
\text { Total }\end{array}$ & $\begin{array}{r}1 \\
1 \\
2 \\
8 \\
12 \\
15 \\
66 \\
107 \\
97 \\
21 \\
318\end{array}$ & $\begin{array}{l}0.03 \\
0.02 \\
0.05 \\
0.26 \\
0.08[0.03-0.12] \\
0.67[0.33-1.01] \\
3.47[2.63-4.31] \\
8.11[6.58-9.64] \\
15.87[12.74-19.00] \\
18.42[10.62-26.23] \\
1.50[1.34-1.66]\end{array}$ & $\begin{array}{r}1 \\
4 \\
4 \\
6 \\
15 \\
10 \\
45 \\
88 \\
131 \\
68 \\
357\end{array}$ & $\begin{array}{l}0.03 \\
0.10 \\
0.12 \\
0.20 \\
0.11[0.06-0.16] \\
0.46[0.17-0.75] \\
2.35[1.66-3.04] \\
5.84[4.62-7.01] \\
13.39[11.11-15.67] \\
20.36[15.57-25.14] \\
1.71[1.53-1.89]\end{array}$ & $\begin{array}{r}2 \\
5 \\
6 \\
14 \\
27 \\
25 \\
111 \\
195 \\
228 \\
89 \\
675\end{array}$ & $\begin{array}{l}0.03 \\
0.06 \\
0.08 \\
0.23 \\
0.09[ \\
0.57[ \\
2.91[ \\
6.90[ \\
14.34[ \\
19.87[ \\
1.60[\end{array}$ & {$\left[\begin{array}{l}0 \\
0.06-0.13] \\
0 \cdot 35-0.79] \\
2.37-3.45] \\
5.93-7.87] \\
{[12.49-16.19]} \\
{[15 \cdot 78-23.95]} \\
1.48-1.72]\end{array}\right.$} \\
\hline
\end{tabular}

$\mathrm{N}=$ number of cases. Rate per 1000 persons and [ $95 \%$ confidence interval].

OCSP incidence rates are compared with those from other studies in fig 5. Figure 6 shows the odds of sustaining a first stroke according to age and sex compared with the odds of dying from ischaemic heart disease. ${ }^{16}$

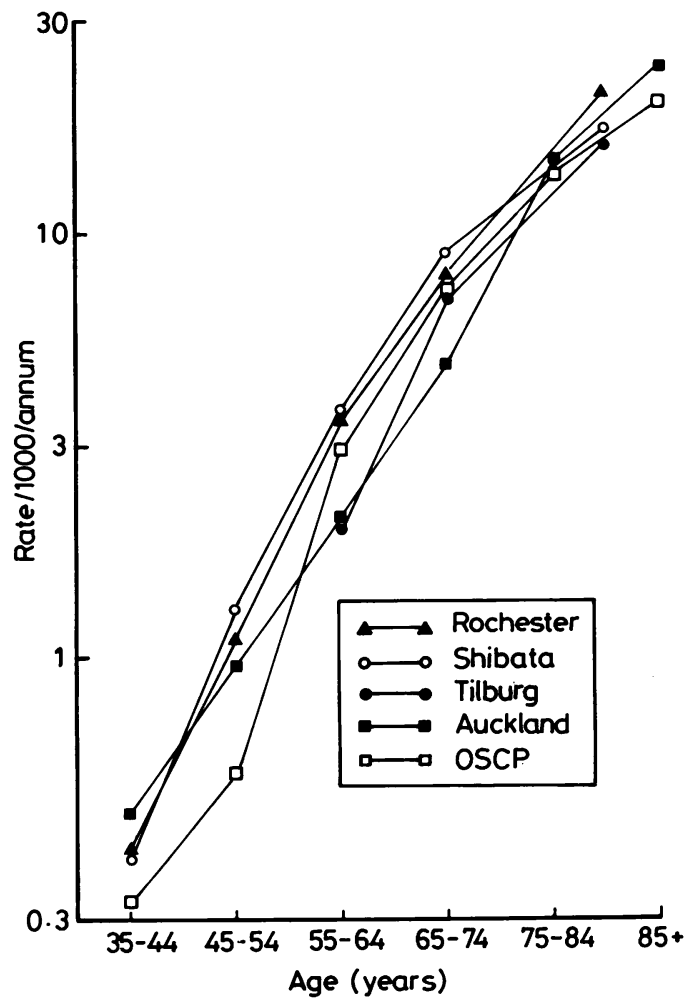

Fig 5 A comparison of the age-specific incidence rates for first-ever stroke (all cases) with other studies (Rochester, ${ }^{2}$ Tilburg, ${ }^{5}$ Shibata, ${ }^{6}$ Auckland.) $)^{27}$ Note the logarithmic scale.

\section{Discussion}

The increasing financial constraint on health care budgets worldwide is likely to focus the attention of health planners and physicians on conditions such as stroke which place a heavy burden on both the individual and the community. ${ }^{17}$ Accurate epidemiological data on incidence, prevalence and outcome are required to plan future services and plan controlled trials of new treatments. In order to be accurate an incidence study should (a) be prospective (b) use a large, representative population whose structure is known accurately (c) obtain complete case ascertainment (d) have early detailed neurological assessments and (e) have a high proportion of cases with confirmed pathology. Few studies have been able to satisfy the majority of these ideals, thereby limiting the utility of the data.

There are features in any health care system which are particularly well suited to certain types of research. The British National Health Service (NHS) system is

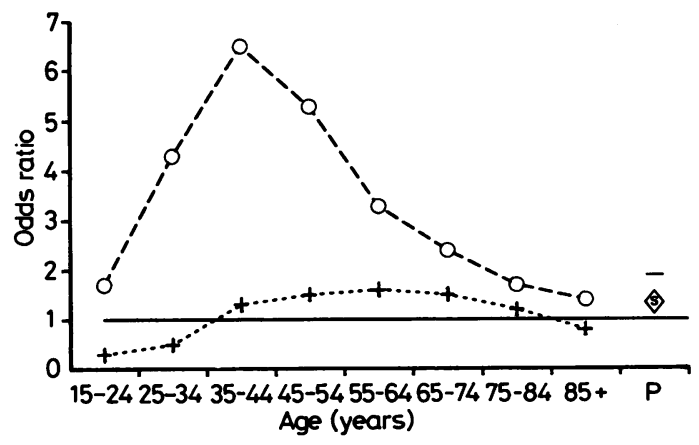

Fig 6 A comparison of the odds of sustaining a first-ever stroke according to sex with those of dying from ischaemic heart disease. ${ }^{16}---0--$ First-ever stroke - - + - Death due to ischaemic heart disease. $P=$ Pooled odds ratio, the vertical size of the symbol representing the $95 \%$ confidence interval. ( $S=$ stroke, $-=I H D)$. 
particularly suited to epidemiological studies since over $98 \%$ of the population is registered with a GP of their choice ${ }^{18}$ who is informed of any contact between a patient and the medical profession. Defining the study population in terms of patients registered with a particular set of GPs allowed sampling of patients from a wider, and thus potentially more representative area than might be studied if the denominator had been defined geographically. The problem of "crossboundary" medical care which might arise because of the reputation of a particular physician or institution, the provision of special services, or the more rapid assessment of patients at a hospital outside the study area was also avoided. Previously, in order to circumvent this problem, relatively isolated communities have been studied (for example, Faroe Islands ${ }^{19}$ ) but the populations have usually been too small for accurate stroke incidence studies particularly of the different pathological types of stroke. Such isolated communities may also have unusual characteristics which limit the extent to which any results may be generally valid. Our practices, though not chosen at random, provided primary health care for the range of rural and urban communities present in Oxfordshire. Although detailed socio-economic data were not available, it is likely that our study population was representative of Oxfordshire as a whole which has a slightly higher socio-economic status than the average for England and Wales. The age and sex structure of our population was broadly similar to that of Oxfordshire and England and Wales as a whole. By collaborating with all the GPs in a number of health centres we negated any tendency for certain types of patient (such as young mothers or elderly patients) to register preferentially with any individual GP.

There are relatively few studies where a population census of the relevant geographical area has been performed at the same time as the study is taking place; more often extrapolations from previous census data are used (for example Rochester ${ }^{12}$ ). By performing a census of the ASRs at the beginning and end of the study period we were able to identify changes in the study denominator. There was a net increase of $5.6 \%$ in the population during the study period, the result of a marked increase in the numbers of young people and a small decrease in those over 65 years of age. Whilst neither the ASR nor the FPC records can be assumed to be $100 \%$ correct at any given time since deaths, births and changes of address take a number of months to be processed, the small discrepancies which we found suggest that the ASRs in the study practices were well maintained and that it was reasonable to base the study population on these figures. ${ }^{20}$

Our results show that GPs can be an extremely reliable source of referral. There were very few instances where a GP appeared to know that a patient had had a stroke but did not notify the study. The large number of patients assessed by the study team but not considered to have had a first-ever stroke or TIA reflected a deliberate policy of the OCSP to encourage GPs to refer all possible cases. A more selective referral policy might have led to patients with more unusual presentations of cerebrovascular disease not being registered. It is important to assess cases of "TIA" as well as "stroke" since at least $7 \%$ of patients had an event classified as a stroke by our standard definition but which had been labelled as a TIA either by a GP or hospital physician. ${ }^{21}$

The proportion of patients with stroke admitted to hospital in different countries varies widely. Some authors claim or infer, without much justification, that virtually all strokes are admitted to hospital in their own region and that they are therefore representative of all strokes occurring in the community. ${ }^{22}$ In Oxfordshire, only $54 \%$ of patients with first-ever stroke were admitted to hospital ${ }^{23}$ and in other UK studies admission rates of $40 \%{ }^{24}$ to $70 \%{ }^{25}$ have been reported. Aho et $a l^{26}$ noted that in the European centres of the WHO study only $75 \%$ of patients were admitted to hospital. In Japan, especially amongst the elderly, the admission rate may be even lower, ${ }^{4}$ a trend that was also noted in New Zealand. ${ }^{27}$ We have shown that cases with primary intracerebral haemorrhage (PICH) are more likely to be admitted than those with cerebral infarction $(\mathrm{CI})^{28}$ and patients with milder clinical deficits (and consequently a lower case fatality rate) are more likely to remain at home..$^{23}$ However, secondary stroke prevention is, potentially, of most benefit to this latter group. Any failure to detect such cases may distort the natural history and influence the perception of how feasible any trial of treatment aimed at secondary prevention might be. The accurate comparison of stroke incidence rates in different countries is impossible unless studies can demonstrate that they have detected most of, if not all, the cases. Using the various checks in our study we are confident that we achieved virtually complete case ascertainment.

The major advantage of hospital-based studies is that they can make detailed neurological assessments from the time of admission and at frequent intervals thereafter. The logistics of our study permitted only a single assessment by a study neurologist, but the median delay from onset to assessment of only 4 days meant that accurate data was obtained about the acute phase of the strokes. The few patients assessed more than 2 weeks after their stroke were often those who were admitted to hospitals whilst they were away from Oxfordshire; in these cases clinical details were also obtained from the original admission records.

Although the technological advances in the last 15 years, particularly CT, have improved the accuracy of 
diagnosis of different pathological types of stroke, such facilities still tend to be orientated towards patients who have contact with hospital based physicians. Community-based studies are not biased towards any particular stroke type but previous studies have either not described the use of CT or have used this investigation in a minority of cases. Many have used only clinical criteria to distinguish $\mathrm{CI}$ and $\mathrm{PICH}$ in the majority of patients yet this is known to be inaccurate. ${ }^{2930}$ The $88 \%$ CT or necropsy rate satisfied the original aims of our study. It is unlikely that this proportion can be significantly increased in UK practice since we were aware of a reasonable reluctance to transport very frail, elderly people to hospital to have CT, particularly if death was imminent and the scan was unlikely to alter their management. Also there was a reluctance on the part of GPs to press for a necropsy in such cases.

The very low proportion of cases who presented with what was considered to be a stroke on clinical grounds yet were found to have some other lesion on CT confirms the reliability of the clinical diagnosis of "stroke". ${ }^{31}$ Also, it makes it unlikely that non-vascular pathology was responsible for the neurological symptoms in those patients who were assessed but did not have CT or necropsy.

Crude annual incidence rates have little value other than establishing the general magnitude of the clinical problem of stroke. We would predict from our results that about 99,000 people will have a first-ever stroke each year in England and Wales. Our data show that the age- and sex-specific incidence rates continue to rise steeply with increasing age even amongst the most elderly which confirms the findings of the Auckland study. ${ }^{27}$ Presenting the incidence rates for the age groups 75-84 years and 85 + years separately allows more confident projections to be made when considering the marked demographic changes that will occur over the next 50 years. Figure 5 shows that the rate of increase of stroke incidence with increasing age appears similar in Europe, North America, Asia and Australasia and no striking geographical variations are apparent.

The technique of pooling odds ratios ${ }^{15}$ to calculate the excess odds of either sex sustaining a first-ever stroke prevents undue emphasis being placed on groups with large denominators but a small number of events. The excess odds of a male sustaining a first-ever stroke of $26 \%(95 \%$ CI $7 \%$ to $47 \%$ ) are similar to those from the Tilburg study ${ }^{5}$ when calculated in a similar way $(+18 \%, 95 \% \mathrm{CI}-1 \%$ to $+41 \%)$ though lower than those in Rochester $^{2}(66 \%, 95 \%$ CI $44 \%$ to $91 \%)$. The massive excess odds of males dying from ischaemic heart disease (fig 6) between the ages of 35 and 55 years is not mirrored for stroke though the subsequent reduction of excess odds in males with increasing age is seen.

In summary, we think that the original aims of the study which were to see all new cases of stroke and TIA in a representative population unbiased by hospital admission, record detailed clinical information and obtain confirmation of the pathological type of stroke have been fulfilled. The patients described above will form the basis of further reports on the incidence and outcome of various pathological subtypes of acute cerebrovascular disease in the community.

This work was supported by grants from the Medical Research Council and the Chest, Heart and Stroke Association. We thank the participating general practitioners and all consultants who allowed us to study their patients, the practice receptionists and nursing staff who helped in many ways and the voluntary car drivers of Oxfordshire who provided invaluable help transporting patients. We gratefully acknowledge the assistance of Drs $P$ Sheldon and $P$ Anslow (neuroradiology), $\mathbf{M}$ Esiri, $\mathbf{M}$ Squier, E Ilgren and $\mathbf{M}$ Rossi (neuropathology), J A M Gray (community medicine) and Ms H Storey, V Langsbury, A Dwyer and A Watts (secretarial).

The participating general practices were (name of liason partner from each practice only): Dr A McPherson, Oxford; Dr A Markus, Thame; Dr D Leggatt, Oxford; Dr M Agass, Berinsfield; Dr D Otterburn, Abingdon; Dr S Street, Kidlington; Dr V Drury, Wantage; Dr R Pinches, Abingdon; Dr N Crossley, Abingdon; Dr H O'Donnell, Deddington.

The study nurses were Mrs S Price, Mrs E Mogridge and Mrs C Clifford.

\section{References}

1 Whisnant JP, Fitzgibbon JP, Kurland LT, Sayre GP. Natural history of stroke in Rochester, Minnesota: 1945 through 1954. Stroke 1971;2:11-22.

2 Matsumoto N, Whisnant JP, Kurland LT, Okazaki H. Natural history of stroke in Rochester, Minnesota: 1955 through 1969: An extension of a previous study, 1945 through 1954. Stroke 1973;4:20-9.

3 Kannel WB, Wolf PA. Epidemiology of cerebrovascular disease. In: Ross Russell RW, ed. Vascular Disease of the Central Nervous System. Edinburgh: Churchill Livingstone, 1983.

4 Ueda K, Omae T, Hirota Y, et al. Decreasing trend in incidence and mortality from stroke in Hisayama residents, Japan. Stroke 1981;12:154-60.

5 Herman B, Leyten ACM, van Luijk JH, Frenken CWGM, de Coul O, Schulte BPM. Epidemiology of stroke in Tilburg, The Netherlands. The population-based stroke incidence register: 2 . Incidence, initial clinical picture and medical care, and three week case fatality. Stroke 1982;13:334-9.

6 Tanaka H, Ueda Y, Date H, et al. Incidence of stroke in Shibata, Japan: 1976-1978. Stroke 1981;12:460-6.

7 Malmgren R, Warlow C, Bamford J, Sandercock P. Geographical and secular trends in stroke incidence. Lancet 1987;ii:1196-200.

8 Garraway WM, Whisnant JP, Drury I. The continuing decline in the incidence of stroke. Mayo Clin Proc 1983;58:520-3. 
9 Acheson ED. In: Medical Record Linkage. London: OUP, 1967.

10 Hatano S. Experience from a multicentre stroke register: a preliminary report. Bull WHO 1976;54:541-53.

11 Warlow CP, Morris PJ. Introduction. In: Warlow CP, Morris PJ, ods. Transient Ischaemic Attacks. New York: Marcel Decker, 1982:vii-xi.

12 Kendall BE, Pullicino P. Intravascular contrast injection in ischaemic lesions. II. Effect and prognosis. Neuroradiology 1980;19:241-3.

13 Nie NH, Hull CH, Jenkins CG, Steinbrenner K, Brent DH. Statistical Package for the Social Sciences. New York: McGraw Hill, 1975.

14 Miettinin OS. Simple interval estimation of risk ratio. Am J Epidemiol 1974;100:515-6.

15 Yusuf S, Peto R, Lewis J, Collins R, Sleight P. Beta blockade during and after myocardial infarction: an overview of the randomized trials. Prog Cardiovascular Dis 1985;27:335-71.

16 Office of Population and Censuses and Surveys. Series DH1, No 14. London: HMSO, 1983.

17 Carstairs V. Stroke: resource consumption and the cost to the community. In: Gillingham FJ, Mawdsley C, Williams AE, eds. Stroke-Proceedings of the Ninth International Pfizer Sympositum. Edinburgh: Churchill Livingstone, 1976.

18 Cartwright A, Anderson R. In: General Practice Revisited. London: Tavistock, 1981.

19 Joensen P. Stroke in an isolated population. Acta Med Scand 1982:212:309-11.

20 Sheldon MG, Rector AL, Barnes PA. The accuracy of age-sex registers in general practice. J $R$ Coll Gen Pract 1984;34:269-71.

21 Oxfordshire Community Stroke Project. Incidence of stroke in
Oxfordshire: first years experience of a community stroke register. Br Med J 1983;287:713-7.

22 Abu-Zheid HAH, Choi NW, Nelson NA. Epidemiologic features of cerebrovascular disease in Manitoba: incidence by age, sex and residence with etiologic implications. Can Med Assoc J 1975;113:379-84.

23 Bamford J, Sandercock P, Warlow C, Gray M. Why are patients with acute stroke admitted to hospital? The experience of the Oxfordshire Community Stroke Project. Br Med J 1986; 292:1369-72.

24 Cochrane AL. Burden of cerebrovascular disease. Br Med J 1970; 274:347.

25 Hewer RL. Stroke rehabilitation. In: Gillingham FJ, Mawdsley C Williams AE, eds. Stroke-Proceedings of the Ninth International Pfizer Symposium. Edinburgh: Churchill Livingstone, 1976.

26 Aho K, Harmsen P, Hatano S, Marquardsen J, Smirnov VE, Strasser T. Cerebrovascular disease in the community: results of the WHO Collaborative Study. Bull WHO 1980;58:113-30.

27 Bonita R, Beaglehole R, North JDK. Event, incidence and case fatality rates of cerebrovascular disease in Auckland, New Zealand. Am J Epidemiol 1984;120:236-43.

28 Dennis MS, Bamford JM, Warlow CP. Strokes amongst black people in Harare, Zimbabwe (letter). Br Med J 1986;293:134.

29 Harrison MJG. Clinical distinction of cerebral haemorrhage and cerebral infarction. Postgrad Med J 1980;56:629-32.

30 Allen CMC. Clinical diagnosis of the acute stroke syndrome. $Q J$ Med 1983;52:515-23.

31 Sandercock P, Molyneux A, Warlow C: Value of computed tomography in patients with stroke: The Oxfordshire Community Stroke Project. Br Med J 1985;250:193-7. 
year prospective study of stroke patients. Stroke 1988 ; 19:942-9.

32 Harmsen P, Wilhelmsen L. Stroke registration in Goteberg, Sweden, 1971-5. Acta Med Scand 1984;215:239-48.

33 Aho K, Harmsen P, Hatano S, Marquardsen J, Smirnov VE, Strasser T. Cerebrovascular disease in the community: results of the WHO Collaborative Study. Bull WHO 1980;58:113-30.

34 Tanaka H, Ueda Y, Date C, et al. Incidence of stroke in Shibata, Japan: 1976-8. Stroke 1981;12:460-6.

35 Tanaka $H$. Age-specific incidence of stroke subtype in Shibata, Japan: 1976-8. Stroke 1982;13:110.
36 Garraway WM, Whisnant JP, Furlan AJ, Phillips LH, Kurland LT, O'Fallon $W M$. The declining incidence of stroke. N Eng J Med 1979;300:449-52.

37 Garraway WM, Whisnant JP, Kurland LT, O'Fallon WM. Changing pattern of cerebral infarction: $1945-4$. Stroke Changing patter

38 Furlan AJ, Whisnant JP, Elveback LR. The decreasing incidence of primary intracerebral haemorrhage: a population study. Ann Neurol 1979;5:367-73.

39 Bamford J, Sandercock P, Warlow C. Fatal ischaemic brain oedema after early thrombolysis with tissue plasminogen activator in acute stroke. $\mathrm{Br} \mathrm{Med} \mathrm{J} \mathrm{1989;298:382-3.}$

\section{ERRATUM}

Bamford J, Sandercock P, Dennis M, et al. A prospective study of acute cerebrovascular disease in the community: the Oxfordshire Community Stroke Project 1981-86. 1. Methodology, demography and incident cases of first-ever stroke. J Neurol Neurosurg Psychiatry 1988;51:1373-80. The symbols on the legend of figure 6 should be reversed so that $--+--=$ firstever stroke and $--O--=$ death due to ischaemic heart disease. 